14

\title{
Влияние $\gamma$-облучения и допирования диоксидом кремния на свойства политетрафторэтилена
}

\author{
(c) В.М. Егоров ${ }^{1}$, П.Н. Якушев ${ }^{1}$, М.А. Арсентьев ${ }^{2,3}$, А.С. Смолянский ${ }^{2,3}$ \\ ${ }^{1}$ Физико-технический институт им. А.Ф. Иофрфе РАН, \\ Санкт-Петербург, Россия \\ ${ }^{2}$ Научно-исследовательский физико-химический институт им. Л.Я. Карпова, \\ Москва, Россия \\ ${ }^{3}$ Российский химико-технологический университет им. Д.И. Менделеева, \\ Москва, Россия \\ E-mail: victor_egorov1@inbox.ru
}

Поступила в Редакцию 28 февраля 2019 г.

В окончательной редакции 28 февраля 2019 г.

Принята к публикации 5 марта 2019 г.

\begin{abstract}
Проведен сравнительный анализ плавления политетрафторэтилена в исходном и облученном состоянии, а также в составе композита с содержанием диоксида кремния растительного происхождения 1\%. Расчет профилей пиков теплоемкости на основе теории размытых фазовых переходов первого рода позволил выявить особенности структурных изменений в композите и облученном политетрафторэтилене. Методом динамического анализа охарактеризован релаксационный $\alpha$-переход стеклования.
\end{abstract}

Ключевые слова: политетрафторэтилен, фазовый переход, калориметрия, радиационное облучение.

DOI: 10.21883/FTT.2019.07.47856.405

Политетрафторэтилен (ПТФЭ) применяется во многих областях промышленности и техники, поскольку он обладает рядом позитивных свойств, в частности, в качестве изоляционного материала он применяется в радио- и электротехнике как один из лучших диэлектриков [1]. Поскольку из всех известных полимеров ПТФЭ наиболее химически стоек и биологически инертен, он находит применение в разных отраслях медицины, в том числе в офтальмологии [2]. В последнее время предпринимаются попытки создания технологии радиационнохимического синтеза новых полимерных композитов на основе политетрафторэтилена (ПТФЭ) и диоксида кремния [3]. Важным моментом при использовании такого рода материалов является прогнозирование их физикомеханических, в частности, прочностных свойств. Последние, как известно, определяются структурными особенностями строения полимера [4].

ПТФЭ при комнатной температуре находится в двухфазном состоянии - частично кристаллическом, в котором наблюдаются термодинамические фазовые переходы, и аморфном (термодинамически-жидком), в котором наблюдаются релаксационные переходы. Оба типа переходов могут быть инициированы различными внешними воздействиями, включая температуру, механические напряжения, гидростатическое давление, электрические и магнитные поля, т.е. реализуются практически во всех процессах получения и переработки полимерных материалов.

Структура ПТФЭ в „климатическом“ температурном диапазоне 200-350 K претерпевает по мере повышения температуры значительные изменения. В кристалличе- ской части полимера вначале происходит двойной фазовый переход из структуры с триклинной элементарной ячейкой $(<293 \mathrm{~K})$ в структуру, поперечная упаковка молекул в которой близка к гексагональной. При этом, конформация цепи в виде спирали с повторяющимся звеном из 6 витков и 13 групп $\mathrm{CF}_{2}$ остается спиралеобразной, а повторяющееся звено увеличивается до 7 витков и 15 групп $\mathrm{CF}_{2}$. Выше $\sim 303 \mathrm{~K}$ возрастает свобода внутренних вращений, вследствие чего определить наличие спирали и повторяющихся звеньев затруднительно. В то же время поперечная упаковка молекул сохраняется близкой к гексагональной вплоть до плавления [5].

Основной релаксационный переход в полимерах $\alpha$-переход стеклования, в температурном интервале которого 400-450 K происходит наиболее кардинальные изменения физических свойств полимеров, в ПТФЭ без внешнего воздействия при нагреве вплоть до температуры плавления не проявляется. В частности, температурная зависимость теплоемкости в пределах $300-500 \mathrm{~K}$ не имеет каких-либо существенных аномалий [6]. Обусловлено это, по-видимому тем, что сегментальное движение в ПТФЭ затруднено жесткостью цепи, статистический сегмент которой $\left(\sim 18\right.$ групп $\left.-\mathrm{CF}_{2}-\right)$ аномально высок для гибкоцепных полимеров. Поэтому для проявления кооперативного движения сегментов, характерного для стеклования, необходимо внешнее воздействие, в том числе, механическим полем. В настоящей работе для исследования $\alpha$-перехода стеклования использовался метод динамического механического анализа (ДМА). 
В качестве образцов для исследования использовался промышленный ПТФЭ марки Ф-4Д производства ОАО „Галоген“. Наполнителем являлся порошкообразный аморфный диоксид кремния изготовленный из рисовой шелухи, содержащий по данным рентгеновской дифракции аморфную фазу до 100\% (производство - ООО „Карборундас““, Республика Литва). Смешивание наночастиц диоксида кремния с порошком ПТФЭ производилось в смесителе. Результаты электронно-микроскопического анализа, полученные с помощью растрового электронного микроскопа Versa $3 \mathrm{D}^{\mathrm{TM}}$ DualBeam $^{\mathrm{TM}}$ показали, что порошки диоксида кремния состоят из нано/микрочастиц разнообразной формы, размеры которых варьируют от нескольких сотен до $<0.1 \mathrm{mkm}$ (рис. 1). Сами частицы представляют собой рыхло-упакованные конгломераты из более мелких частиц, и содержат многочисленные поры размером 2-4nm [3]. Попытки радиационного модифицирования ПТФЭ при комнатной температуре в среде воздуха и в вакууме для улучшения его свойств не дали практически значимых результатов [7]. Между тем было показано, что облучение политетрафторэтилена при температуре выше температуры плавления кристаллической фазы приводит к получению новых модификаций полимера, обладающих необычными свойствами [8]. Поэтому в настоящей работе радиационную обработку ПТФЭ проводили при температурах от 330 до $370^{\circ} \mathrm{C}$ в атмосфере азота с использованием гамма-излучения изотопа ${ }^{60} \mathrm{Co}(1.25 \mathrm{MeV})$. Расчет дозы $\gamma$-излучения, поглощенной композитом на основе ПТФЭ с добавкой диоксида кремния, проводили согласно требованиям ГОСТ 27602-88.

Динамический механический анализ исследуемых образцов проводился на модуле DMS6100 рабочей станции EXSTAR6000 фирмы Seiko Instruments. Образцы в виде цилиндров диаметра $3 \mathrm{~mm}$ и длины $6 \mathrm{~mm}$ испытывались

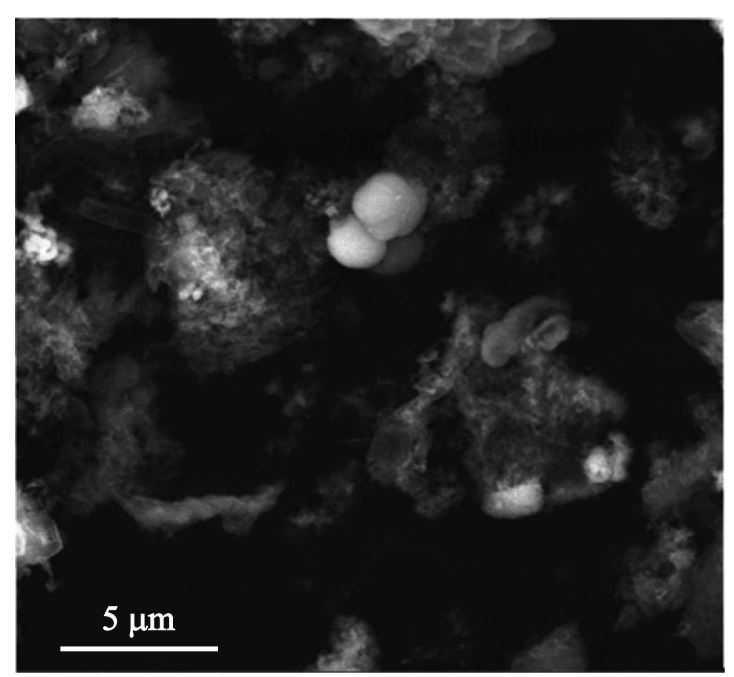

Рис. 1. Электронно-микроскопический снимок композита на основе ПТФЭ с добавкой $1 \% \mathrm{SiO}_{2}$.

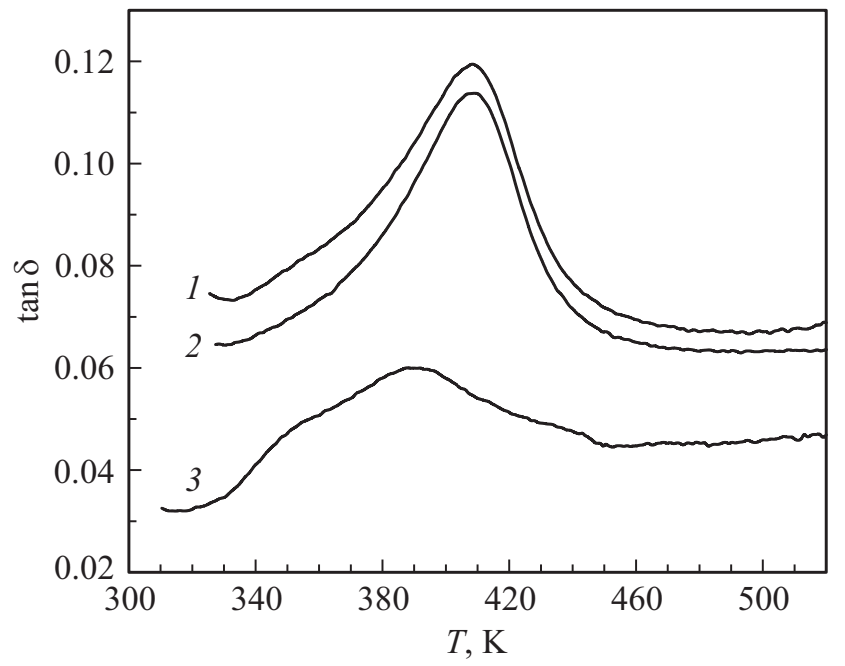

Рис. 2. Зависимость $\tan \delta=f(T)$ образцов исходного ПТФЭ (1), наполненного диоксидом кремния (2) и облученного (3).

в режиме синусоидального приложения нагрузки сжатия с частотой $1 \mathrm{~Hz}$ при нагревании со скоростью $2 \mathrm{~K} / \mathrm{min}$ в интервале температур $\alpha$-перехода стеклования. На рис. 2 представлены полученные в работе зависимости $\tan \delta=f(T)$. Наибольшие динамические потери, проявляющиеся в виде пиков на кривой $\tan \delta=f(T)$, наблюдаются в исходном ПТФЭ (кривая 1).

Допирование исходного ПТФЭ диоксидом кремния вызывает незначительное уменьшение амплитуды пика, при этом форма пика аналогична форме пика исходного ПТФЭ (кривая 2). Результаты испытаний облученного ПТФЭ сильно отличаются от двух предыдущих случаев. Видно (кривая 3), что облучение приводит к значительному уменьшению амплитуды пика и его формы. При этом форма пика показывает сложное строение, которое, по-видимому, отражает более сложную надмолекулярную структуру аморфной части облученного полимера в сравнении с исходным и допированным полимерами.

В отличие от данных по динамическим потерям, полученным при активном воздействии на полимер механической нагрузки, на зависимости теплоемкости от температуры $C_{p}(T)$, как отмечалось выше, релаксационный переход стеклования выражен очень слабо. Наиболее информативными данными по теплоемкости для исследуемых объектов являются зависимости теплоемкости от температуры $C_{p}(T)$ в температурном диапазоне плавления. Перед изложением этих данных необходимо сделать предварительное замечание. Известно [9], что при использовании метода ДСК (дифференциальная сканирующая калориметрия) возникают методические погрешности, связанные с наличием термосопротивления испытываемого образца в калориметрической ячейке, которое существенно зависит от массы образца и скорости сканирования. В настоящей работе эти методические погрешности устранены [6]. 
Термодинамические данные и параметры расчета по соотношениям (1) и (2)

\begin{tabular}{|c|c|c|c|c|c|c|c|c|c|}
\hline \multirow{2}{*}{ Образец } & $T_{m}$ & $\Delta H_{\Sigma}$ & $\Delta C_{p \max }$ & $B$ & $q_{0}$ & $\chi$ & $\Delta T$ & $v$ & $L$ \\
\hline & $\mathrm{K}$ & $\mathrm{Jg}^{-1}$ & $\mathrm{Jg}^{-1} \mathrm{~K}^{-1}$ & & $\mathrm{Jg}^{-1}$ & $\%$ & $\mathrm{~K}$ & & $\mathrm{~nm}$ \\
\hline ПТФЭ & 594.7 & 34.5 & 3.9 & 750 & 12.4 & 18 & 3.3 & 520 & 65 \\
\hline$\Pi Т Ф Э+\mathrm{SiO}_{2}(1 \%)$ & $\begin{array}{l}593.0 \\
570.1\end{array}$ & 32.8 & $\begin{array}{c}4.2 \\
0.06\end{array}$ & $\begin{array}{l}850 \\
400\end{array}$ & $\begin{array}{l}11.8 \\
0.34\end{array}$ & 16 & $\begin{array}{c}3.4 \\
10-12\end{array}$ & $\begin{array}{c}500 \\
120-135\end{array}$ & $\begin{array}{c}62 \\
15-17\end{array}$ \\
\hline $\begin{array}{l}\text { ПТФЭ+ } \mathrm{SiO}_{2}(1 \%) \\
+\gamma \text {-облучение } \\
\text { при } 350^{\circ} \mathrm{C}\end{array}$ & $\begin{array}{l}582.1 \\
587.5\end{array}$ & 36.6 & $\begin{array}{l}2.5 \\
1.3\end{array}$ & $\begin{array}{l}300 \\
650\end{array}$ & $\begin{array}{c}19.8 \\
5.1\end{array}$ & 36 & $\begin{array}{l}8.5 \\
4.2\end{array}$ & $\begin{array}{l}190 \\
400\end{array}$ & $\begin{array}{l}24 \\
50\end{array}$ \\
\hline
\end{tabular}

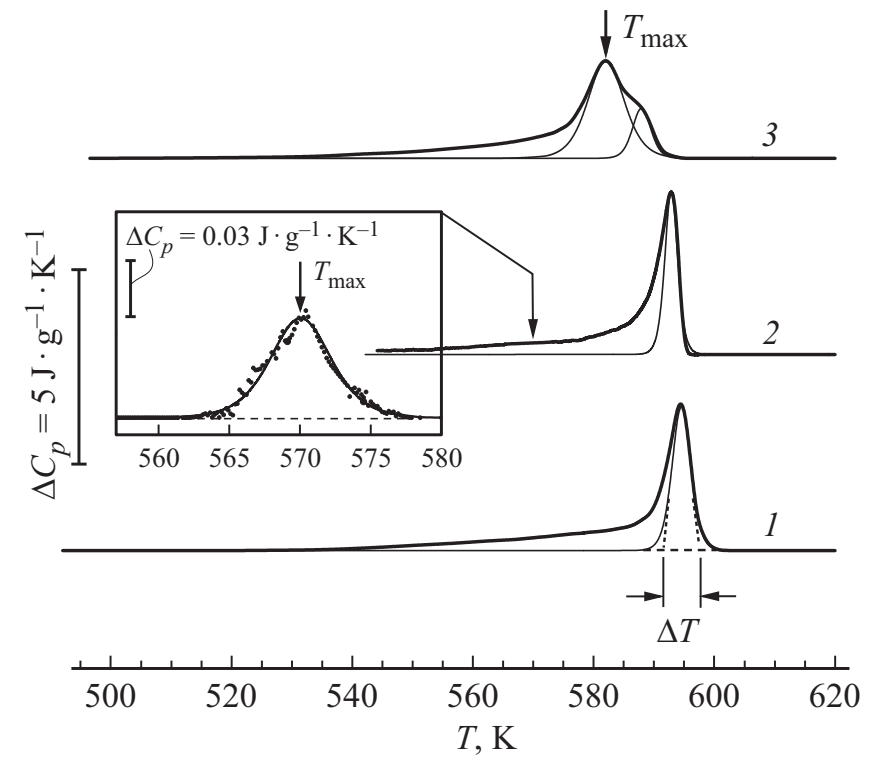

Рис. 3. Кривые ДСК, полученные при нагревании образцов исходного ПТФЭ (1), ПТФЭ с наполнителем - диоксидом кремния (2) и облученного ПТФЭ (3). Тонкие линии - расчет по соотношению [1]. На вкладке - локальный максимум, указанный стрелкой на кривой (2).

На представленных зависимостях $C_{p}(T)$ (рис. 3), полученных методом ДСК, видны эндотермические эффекты в широком температурном диапазоне $\sim 500-600 \mathrm{~K}$. Наряду со сравнительно узкими пиками плавления $\Lambda$-образной формы видны широкие эндотермические „плечи“, примыкающие к этим пикам со стороны низких температур. Природа возникновения этих „плеч“ связана с возникновением молекулярной подвижности в неупорядоченных областях полимера. Эти неупорядоченные области расположены между кристаллическими сердечниками ламелей и содержат в себе группы молекулярных элементов, таких как нерегулярные петли, свернутые и слабоизогнутые проходные цепи, длинные концы молекул, выходящие из кристалла. В температурной области примыкания „плеча“ к пику плавления размораживается сегментальная подвижность в предельновыпрямленных проходных цепях, за которым следует начало плавления [10].
По экспериментальной зависимости $C_{p}(T)$ определены энтальпии эндотермических эффектов по соотношению $\Delta H_{\Sigma}=\int C_{p}(T) d T$. Значения этих параметров и температуры максимумов пиков плавления $T_{m}$ приведены в таблице.

Информация о физической природе плавления как фазового перехода первого рода может быть получена при анализе формы пика теплоемкости на основе теории самосогласованного поля применительно к $\Lambda$-образным размытым переходам $[11,12]$. Тот факт, что переход становится размытым, означает, что изменение фазового состояния происходит не внезапно, но постепенно, и осуществляется в пределах определенного температурного интервала. Это и приводит к размытию перехода по температуре. В работе [13] получено соотношение для температурной зависимости теплоемкости при размытом фазовом переходе в виде

$$
\begin{aligned}
\Delta C_{p}(T)= & 4 \Delta C_{p \max } \exp \left(B \frac{T-T_{m}}{T_{m}}\right) \\
& \times\left(1+\exp \left(B \frac{T-T_{m}}{T_{m}}\right)\right)^{-2},
\end{aligned}
$$

где $T_{m}$ - температура фазового перехода первого рода, $\Delta C_{p \max }-$ максимальное значение теплоемкости при $T=T_{m}, B-$ атермический параметр.

Расчет теплоемкости по соотношению (1) производился по значениям $T_{0}$ и $\Delta C_{\max }$, соответствующим температуре и амплитуде максимума пика указанным в таблице. Результат расчета приведен на рис. 3 в виде тонких линий. Наилучшее совпадение расчетных и экспериментальных зависимостей наблюдалось при значении параметра $B$ указанном в таблице. Там же приведены значения степени кристалличности $(\chi)$, определенные по соотношению $\chi=100 q_{0} / \Delta H_{0}$, где $q_{0}-$ энтальпия плавления, полученная по расчетным кривым; $\Delta H_{0}=69 \mathrm{Jg}^{-1}-$ энтальпия плавления совершенного кристалла ПТФЭ [5].

Данные ДСК использовались для оценки еще одной характеристики надмолекулярной структуры полимеров - параметра внутрицепной кооперативности плавления $(v)$, физический смысл которого состоит в том, что он определяет минимальную последовательность 
из $v$ повторяющихся звеньев в цепи, переходящих как целое из кристаллита в свернутое состояние статистического клубка в расплаве $[14,15]$. Оценка $v$ производилась по формуле

$$
v=2 R \frac{T_{m}^{2}}{\Delta T \cdot \Delta H_{0}}
$$

где $R$ - газовая постоянная, $\Delta T-$ температурный интервал плавления (см. рис. 3). Безразмерный параметр $v$ выражается числом $\mathrm{CF}_{2}$-групп в транс-участке цепи ПТФЭ, одновременно участвующих в акте плавления. Если умножить $v$ на длину единичной связи $\mathrm{C}-\mathrm{C}$ (размер проекции $\mathrm{C}-\mathrm{C}$-связи основной цепи на ось макромолекулы $h=0.124 \mathrm{~nm}$ ), то этот параметр $L=v h$ можно сопоставлять с размерами ламелярных кристаллов. В таблице приведены данные по $L$, сравнение которых можно провести, основываясь на известном соотношении Томсона-Гиббса [5] для ламелярных кристаллов

$$
T_{m}=T_{0} \frac{1-2 \gamma}{\Delta H_{0} \rho L}
$$

где $L-$ толщина ламели, $\rho-$ плотность, $\gamma-$ торцевая поверхностная энергия, $T_{0}=600.2 \mathrm{~K}$ - температура плавления равновесного бесконечного кристалла ПТФЭ [5]. Боковой поверхностной энергией при этом пренебрегают, поскольку при достаточно больших поперечных размерах ламели площадь торцевой поверхности значительно больше боковой поверхности.

На рис. 4 представлена зависимость $T_{m}=f(1 / L)$, построенная по данным, приведенным в таблице. Видно, что эта зависимость имеет линейный характер и удовлетворяет уравнению (3). Экстраполяция этой прямой приводит к $T_{m}=600.2 \pm 0.5 \mathrm{~K}$, соответствующей равновесной температуре плавления кристаллов. Исключение составляет соотношение $T_{m}=f(1 / L)$ для высокотемпе-

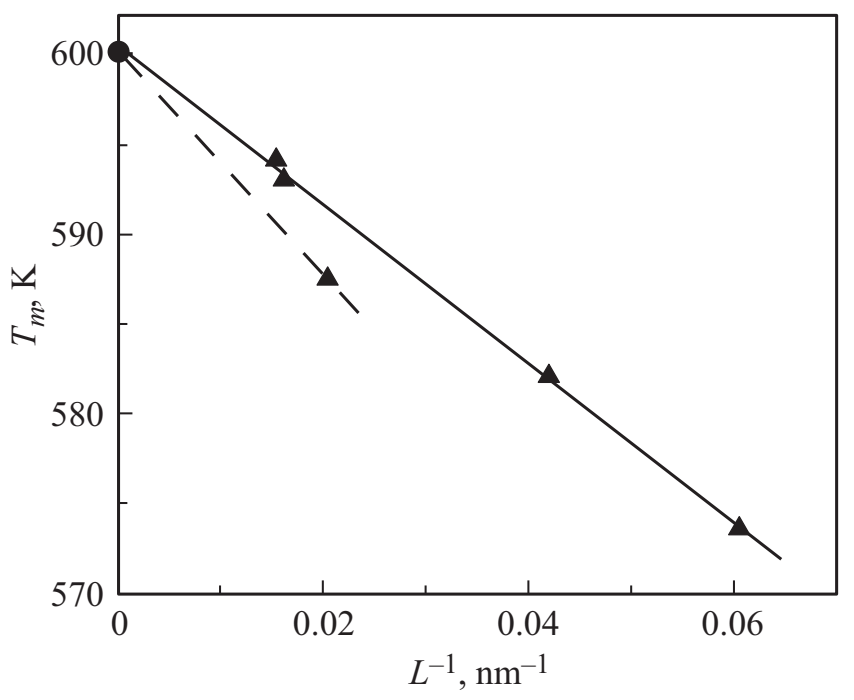

Рис. 4. Зависимость температуры плавления $T_{m}$ от параметpa $L^{-1}$.

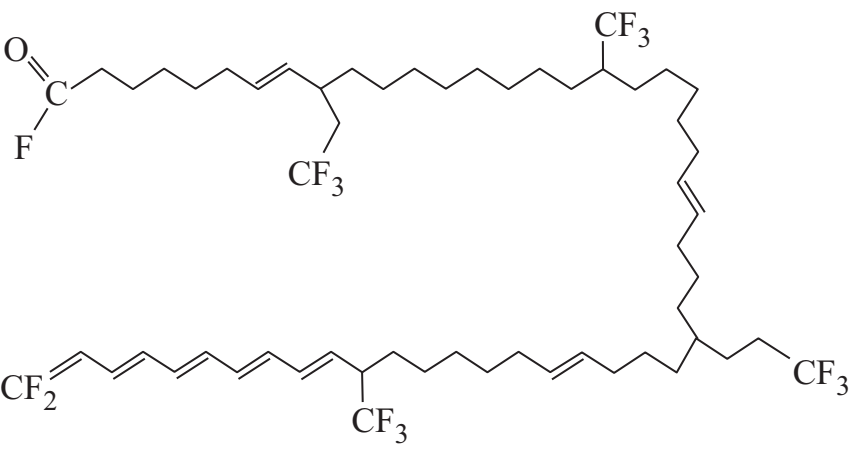

Рис. 5. Обобщенная структура полимерной цепи облученного ПТФЭ [16].

ратурного пика в дублете пика плавления облученного ПТФЭ. Поскольку наклон зависимости определяется величиной поверхностной энергии, можно объяснить это исключение повышенной поверхностной энергией в части ( 25\%) полимера.

Для выяснения причины повышения поверхностной энергии в части кристаллитов облученного ПТФЭ необходимо рассмотреть структуру облученного ПТФЭ. На рис. 5 изображена обобщенная структура полимерной цепи облученного ПТФЭ [16]. При радиационном облучении политетрафторэтилена происходит деструкция основных цепей полимера, уменьшение размеров кристаллитов, снижение пористости, накопление концевых $\left(-\mathrm{CFO}\right.$ и $\left.-\mathrm{CF}_{3}\right)$ групп и серединных двойных связей. Происходит также разветвление цепей и замыкание этих разветвлений на соседние параллельно уложенные в кристаллите молекулы. Последние, по-видимому, и приводят к повышению поверхностной энергии кристаллитов.

Проведенный сравнительный анализ свойств политетрафторэтилена в исходном состоянии и в составе композита с допантом в виде диоксида кремния показал, что допирование приводит к незначительным изменениям структуры ПТФЭ. Эти изменения касаются появления небольшой доли $(<3 \%)$ кристаллитов с продольным размером, в четыре раза меньшим, чем размеры исходных кристаллитов ПТФЭ. Причина их появления очевидно связана с $\mathrm{SiO}_{2}$, но с каким из механизмов взаимодействия допанта с полимером, исходя из полученных данных выяснить невозможно. В случае с облученным ПТФЭ можно констатировать, что облучение подавляет молекулярную подвижность в аморфной части полимера, уменьшает размеры кристаллитов и приводит к появлению кристаллитов с повышенной поверхностной энергией.

\section{Конфликт интересов}

Авторы заявляют, что у них нет конфликта интересов. 


\section{Список литературы}

[1] Ю.К. Машков, 3.Н. Овчар, В.И. Суриков, Л.Ф. Калистратова. Композиционные материалы на основе политетрафторэтилена. Машиностроение, М. (2005). 239 с.

[2] В.П. Николаенко, Ю.С. Астахов. Офтальмология 2, 34 (2005).

[3] А.Ю. Рашковский, Е.Д. Политова, А.О. Меркушкин, М.А. Арсентьев, Е.В. Масленкова, А.С. Смолянский. Безопасность в техносфере 1, 38 (2018).

[4] В.Р. Регель, А.И. Слуцкер, Э.Е. Томашевский. Кинетическая природа прочности твердых тел. Наука, М. (1974). $560 \mathrm{c}$.

[5] Б. Вундерлих. Физика макромолекул. Мир, М. (1984). Т. 3, $479 \mathrm{c}$.

[6] В.М. Егоров, П.Н. Якушев. ФТТ 60, 9, 1824 (2018).

[7] Н.П. Истомин, А.П. Семенов. Антифрикционные свойства композиционных материалов на основе фторполимеров. Наука, М. (1981). 460 с.

[8] J.Z. Sun, Y.F. Zhang, X.G. Zhong. Polymer 35, 2881 (1994).

[9] K. Illers. Eur. Polym. J. 10, 911 (1974).

[10] V.A. Bershtein, V.M. Egorov. Differential Scanning Calorimetry of Polymers: Physics, Chemistry, Analysis, Technology. Ellis Horwood, N.Y. (1994). 253 p.

[11] Б.Н. Ролов, В.Э. Юркевич. Физика размытых фазовых переходов. Изд-во Рост. ун-та, Ростов (1983). 310 с.

[12] Г.А. Малыгин. Успехи физ. наук. 171, 187 (2001).

[13] Г.А. Малыгин. ФТТ 43, 1911 (2001).

[14] P. Flory. J. Pol. Sci. B 49, 105 (1961).

[15] С.Я. Френкель. Энциклопедия полимеров. Сов. энциклопедия, М. (1974). Т. 2. С. 100.

[16] С.А. Хатипов, Е.М. Конова, Н.А. Артамонов. Рос. хим. журн. 5, 64 (2008).

Редактор К.В. Емцев 